\title{
correspondence
}

\section{Melatonin in serum}

SIR,-We have recently completed a preliminary collaborative study of radioimmunoassay methods in the determination of melatonin in serum in which the different techniques used in seven laboratories were compared. To each laboratory we sent the same material derived from calf serum with a melatonin level of less than $10 \mathrm{ng}$ per 1. To this serum melatonin was added in a final concentration of $200 \mathrm{ng}$ per 1 or $0.86 \mathrm{nmol}$ per 1 . Three $\mathrm{ml}$ aliquots of the calf serum from the pool were pipetted into glass ampoules. The calf serum in each ampoule was lyophylised and the ampoules were tightly sealed. The serum was dissolved in $3.00 \mathrm{ml}$ of water and melatonin was assayed in 35 samples from 8 ampoules and was found to be $0.87 \mathrm{nmol}$ per $1 \pm$ $12.9 \%$ r.s.d. by our own radioimmunoassay.

Twenty ampoules were sent in December 1976 to each laboratory. They were requested to add $3.00 \mathrm{ml}$ of water to each ampoule and to perform assays using their own method, reporting back the results in ng melatonin per 1 redissolved calf serum. The results of the different assays are given in Table 1, and are presented as ng per 1 and are also transformed to nmol per 1 according to the SI-system. It should be pointed out that the extraction techniques in the methods differed considerably between the different laboratories and that each laboratory used its own antiserum except for numbers 4 and 5 who used the same one.

The results indicate that melatonin can be measured accurately using different radioimmunoassay techniques. We now intend to repeat and extend the study to include human reference serum with different concentrations of melatonin. This will allow an evaluation of the linearity and parallelism of the standard curves, as well as give

further data on the sensitivity and specificity of the different assays. All laboratories wishing to participate in the extensive cross-validation study planned at the beginning of 1978 are welcome to submit their names to us. LENNART WETTERBERG

\section{Karolinska Institute,}

St Goran's Hospital,

Box 12500, S-I1281,

Stockholm,

Sweden

\section{Technics rather than technik}

SIR,--I thoroughly agree with what Fores and Rey wrote (1 September, page 2) about the need for making a clear distinction between science and what they propose to call Technik. However, I should like to point out that a well-established, but now little used, word already exists in the English language for the concept of the useful arts. This is technics, and I would urge the revival of this old English word, rather than the importation of a foreign-sounding one, to describe this area of our culture.

Lewis Mumford's use of it throughout his great book Technics and Civilisation (1934, Routledge) bears out what Fores and Rey say about the need for a word to express this concept; for Mumford, unlike Bronowski and Mazlish, does not make the mistake of confusing science and technics. As he says, "science and technics form two independent yet related worlds: sometimes converging, sometimes drawing apart".

As Fores and Rey indicate, this distinction is as important in current discussions and controversies concerning the place of science and technics in contemporary culture and society as it is in historical studies. Much current discussion of the financing, control and effects of 'science' would be far less

Comparison of different radioimmunoassays for melatonin

Laboratory Number

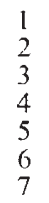

Mean s.d. of all 7
Melatonin concentration of reference calf serum containing $200 \mathrm{ng}$ per 1 or $0.86 \mathrm{n}$ mol per $\mathrm{l}$. pg per $\mathrm{ml}$ nmol per 1

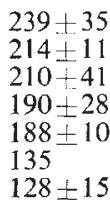

$1.03 \pm 0.15$

$0.92+0.04$

$0.90 \pm 0.18$

$0.82 \pm 0.12$

$0.81 \pm 0.04$

0.58

$0.55 \pm 0.06$

$186 \pm 41$ woolly-minded if a clearer distinction were made between science and technics. However, the lack of a familiar word to express the idea of technics is I think only part of the problem. Equally important is the (perhaps only partly conscious) desire by many scientists and others deliberately to blur the distinction, and to claim for 'science' and scientists the credit for all the benefits resulting from technics.

This shortsighted attitude may have boosted funding and respect for science in the short run but in the longer run, as people become more critical of technology, it is in part responsible for the increasing disillusion with science and the growth of antiscience movements. The antiscience critics are even more at fault for failing not only to make a distinction between science and technics, but also between these and the sociopolitical decisions which have led to particular technical developments that they dislike, and for which we are all responsible as citizens, whether scientists, technicians (surely a better word than Techniker, if its status can be raised) or layman. For a healthy society and a healthy science I believe we should support those, like Sir Andrew Huxley (29 September, page 366), who insist on making these important, but often unpopular, distinctions.

\section{T. Cavalier-Smith}

University of London King's College, $U K$

\section{The Messinian crisis}

SIR,--Just a thought or two on "The Messinian salinity crisis ... etc" by Adams, Benson, Kidd, Ryan and Wright (29 September, page 383).

A Crisis-a word often seen in the news, Is a term which most journalists

frequently use

With reference to sterling or else to a ban On the import of Datsuns from far off

But vaporisation of Miocene seas Japan.

Is a natural process and nothing like these; Evaporite bodies will oft mark the coast Of an ancestral ocean which gave up the ghost.

Applying that hackneyed and trite little

To a normal event is quite clearly absurd. Else what might we see if left up to the PressThe Messinian Horror or Shocker or

ANON 